\title{
SOCIO-CULTURAL ASPECTS OF KURUMBAS IN THE NILGIRI DISTRICT - A STUDY
}

\section{KASTURI ${ }^{1} \&$ DR. KANAGAMBAL ${ }^{2}$}

${ }^{1}$ Ph.D. Scholar, Dept. of History, Govt. Arts College, Udhagamandalam, The Nilgiris. Tamil Nadu, India.

${ }^{2}$ Asst. Professor and Head, Dept. of History, Govt. Arts College, Udhagamandalam, The Nilgiris, Tamil Nadu, India.

\begin{tabular}{l}
\hline ABSTRACT \\
Kurumbas are a recognised scheduled tribe in Kerala and Tamil Nadu. They are one of the earliest known inhabitants \\
of the Western Ghats, collecting and harvesting forest produce, primarily wild honey and wax. They have traditionally \\
subsisted as hunters and gatherers. They live in jungles on the plateau's steep edge, where they conduct shifting \\
agriculture as well as feeding and catching tiny birds and animals. Historically, the Kurumbas and other tribes have \\
enjoyed a cooperative relationship that includes the trading of commodities and services. Members of this group are \\
short, have a dark complexion and prominent brows of their community practise Hinduism and speak a language that is \\
a hybrid of Dravidian dialects. \\
\hline KEYWORDS: Intricate Interpretation and Scrutiny of Bygone Occurrences
\end{tabular}

Received: Jun 01, 2021; Accepted: Jun 21, 2021; Published: Jun 29, 2021; Paper Id.: IJHRDEC20212

\section{INTRODUCTION}

The history of people who settled in the Nilgiris hills has been documented for ages. The Blue Mountains were most likely named for the abundant blue strobilanthes flowers that bloomed in the area's foggy atmosphere. The indigenous tribal peoples of the Toda, Kota, Kurumbas, and Irula have long lived in this area. The Todas and Kota, who are culturally, linguistically, and genetically related, were stationed on the outskirts of the Nilgiri Plateau as sentries to the centre area.

The Kurumbas, who reside in the Nilgiris or Blue Mountains, have a perplexing and mysterious identity. A number of things contribute to the romanticization of these aboriginal people. The word "Kurumba," like the mountain ranges, is found throughout the neighbouring states of Tamil Nadu, Karnataka, and Kerala Kurumbas prefer to be referred to as Kurumbas, although some refer to them as kurumba, kurempa, and kuruman. Kurumba is an etymological term that means "one who looks after sheep." Kurumba tribes in Nilgiris area are known by numerous names, including Kuruman, Kurumba, and Kurubael. The Kurumbas of the hills are one of the scattered remains of countless tiny tribesThe tribes were once a prominent people who belonged to a race descended from nomadic shepherds. They are descended from one of the big Dravidian groups who lived on the Peninsula of South India prior to the historical period. Kurumbas is a shepherd's name.

\section{The Principles of Tribal Society}

Agriculture and hunting are their main sources of income. They primarily inhabit the forest, desert, hilly terrain, and other regions that are inaccessible to the general public.

\section{The Tribal Society}

A tribe is a group of individuals in a rudimentary and laborious stage of development who recognise the authority of a leader 
and usually perceive themselves as descended from a common ancestor.

\section{The Primary Problem of the Tribal Community}

Tribal superstitions and prejudices, acute poverty, nomadic lifestyles of certain tribes, lack of interest in alien subjects taught in an alien language, and a lack of suitable teachers and other facilities in the tribal territory are among the issues.

\section{The Primary Problem of the Tribal Community}

Tribal superstitions and prejudices, acute poverty, nomadic lifestyles of certain tribes, lack of interest in alien subjects taught in an alien language, and a lack of suitable teachers and other facilities in the tribal territory are among the issues. There are approximately 15,000 Kurumbas, with approximately one-third of them residing in the Nilgiri District. Others can be found throughout Southern India. Kurumbas were counted in the 1971 Indian census at 12,930 people. The Nilgiris District census of 1981 counted 4,874 Kurumbas, the majority of them are Muduga.

\section{Divisions of Kurumbas Tribes}

The three classes among the Kurumbas are Mullu Kurumbas Naya Kurumbas, Pania Kurumbas. Breeks further expressed that Kurumbas under 12 categories, They are, Botta, Eda, Karmadia, Kurumba Okkiliyan, Mare Kurumbas, Mullu Kurumbas, Anda Kurumbas, Naya Kurumbas, Kurali Kurumbas, Malsar, Pania and Jain Kurumbas.

\section{Households and Food}

A typical Alu Kurumba village, motta, or kombai, consisting of five or six homes distributed on steep wooded slopes. Built on a bamboo backbone with crisscrossing bamboo stripe and glass walls that are typically strengthened with mud and cow dung and support a tiled roof. Steel jars have replaced traditional bamboo vessels, and leaves have been utilised to create flattened verandhas or thinnumonne, which are used for social purposes. The Kurumbas collected honey and grew little patches of Ragi, Saamai, and other grains.

\section{Religion}

Regardless of their way of life, Kurumbas have their own set of customs and religious rites. The most important of these is an annual celebration honouring their three caste deities, Kallatha, Airu Billi, and Kadu Billalla. They observe the burial custom, which includes complex death rites that change according to gender, age, and rank. The dead are often buried in a sitting position, but the very elderly are incinerated.

\section{Clothes and Accessories}

The Kurumbas adorn themselves with silver and bronze jewellery. Kurumba women traditionally get a few parallel lines of dot tattooed on their foreheads. Women who were married were tali. Traditional Kurumba clothing consisted of a piece of cloth wrapped around the arms. They put it on by folding it on top, creating a cushioned effect that extends up to their knees. The men were dressed in loincloths.

\section{Dance and Music}

Kurumbas have an oral heritage that is expressed through songs, stories, and rhymes. The Kurumbas and other Nilgiri tribes share a musical culture. Their most popular musical instruments are bamboo pipes (Kolu and Bugiri), mono faced drums (Tambatte), and two faced drums. Their topics are either devotional or have something to do with marriage and death ceremonies. They do two styles of dance: the Gantesaattam, which is performed by males, and the Yennattam, which is 
performed by women. Only men perform in the theatre or kuthu, which is usually staged in firelight or under the moonlight and deals with religious and societal issues with a comedic bent. The men are the only ones who play both the feminine and male roles.

\section{Art}

The Kurumbas' art reflects their socio-religious structure. The male members of the temple caretakers, or priests to the Kurumba community, have long practised the skill. The women of the household help to decorate the house by making borders around the door and windows and kolams on the floor. Kurumbas other than temple caretakers are not permitted to perform the skill. The outer walls of the temple and the house serve as the painting's canvas. The figures reflect their Gods and express Kurumba beliefs as well as village and tribe milestones. The artist also draws on his own life for inspiration. The figures are formed out of lines and have a simple design. The primary features of their drawings are independent lines and concentric dots with simple geometric patterns. The figures are similarly devoid of any indication of their natural surroundings. The surface on which they are painted serves as the defining environment. They traditionally sketch with four colours. Red and white soil (Bodhi mann), black produced from tree bark (Kari maran), and green obtained from plant leaves (Kaatavaraisedi). The colours are applied to the walls with a cloth.

\section{Organisations Political and Social}

The community is run by a muthali or ejaman, who is assisted by three assistants: one who specialises in agricultural difficulties, one who specialises in marriage issues, and a third who serves as a messenger or spokesman. A village council, or urkuttam, also makes decisions, particularly concerning marriage. Following the groom's father's initial interest, a feast is prepared at which the girl and boy meet. To cement the marriage, the bride's father receives a memento of beetle leaves and an amount of Rs.101.25 (traditionally Rs.12.5). This price is very important. If the husband fails to pay this amount throughout his wife's lifetime, he loses the right to fulfil the last rights for her. Although the Kurumbas accept exogamous clans, they will frown upon the marriage and may fine or boycott them. The Kurumbas are a patrilineal society in which property is passed down from father to son. After marriage, girls might keep their kula or clan identify. This enables them to rejoin their parent's home after the death of their husband.

\section{CONCLUSIONS}

India has the second highest number of tribal people after Africa. The term tribe can be defined in a variety of ways. Anthropologists define tribes as groups of families whose members speak the same language, live in the same area, observe marriage and occupation taboos, and have a well-developed reciprocal exchange system. When adverse seasonal conditions persist, tribal communities are more likely to incur debt. As a result, tribal borrowers are born in debt. Moneylenders readily provide security. Personal human interaction between the money lender and the tribal debtor is also a significant aspect. It is definitely the most challenging one to handle.

The study of Kurumbas in the Nilgiri district suggests that the majority of Alu Kurumbas are content as wage workers. They believe that their current economic status is better than in the past because of wage money. Husband and wife's income kept them out of poverty and depression. At the same time, they believe that Badagas culturally dominate them, and that Badagas alienate the Alu kurumbas by accusations of sorcery and black magic. Their unseen enemies are depicted in their folk ballads as Alu kurumbas. According to the findings of this study, the Kurumbas still retain a portion of their traditional culture and have not totally accepted the modern monetary economic system. 


\section{REFERENCES}

1. Breeks, W.J. The Tribes and Monuments of The Nilgiris. Madras.

2. Tashi Dolkar \& Hummara Azim, "Socio-Cultural Environment of Changpa Nomads of Changthang Region (Ladakh)”, International Journal of Agricultural Science and Research (IJASR), Vol. 7, Issue 4,pp, 491-496

3. Francis, W. Madras District Gazetteers The Niligiris, Madras.

4. Feki Misbah \& Berhanu Belay, "Livelihood and Socio-Cultural Significance of Afar Goat Breed Intended for Breed Improvement Programs",Journal of Agricultural Science and Research (JASR) Vol. 3, Issue 2,pp, 13-22

5. Gates, Ruggles R. Kurumbas on the Niligiri Hills of Southern India.

6. Hockings, Paul. Blue Mountains: The Ethnography and Biogeography of a South India Region. New Delhi.

7. Noor Uddin Ahmed, “Existence of Arabic 'Adab' (Belles-Lettres): A Linguistic Study”,International Journal of Linguistics and Literature (IJLL), Vol. 5, Issue 5,pp; 1-10

8. Kapp, Dieter B. The Kurumbas Relationship to the Megalithic Cult of the Niligiri Hills. 1985.

9. Ramandeep Kaur, “British Diaspora: Representations of India in Colonial British-Indian Poetry”,International Journal of Linguistics and Literature (IJLL),Vol. 7, Issue 4,pp; 39-46

10. King, Ross W. Aboriginal Tribes of the Niligiris Hills.

11. Misra, Rajalakshmi. The MulluKurumbas In Blue Mountains. 1989.

12. Parthasarathy,Jakka. Kurumbas of Nilgiri District. Tamilnadu HADP publication:Udhagamandalam, 2003. 